\title{
Campo psicossocial e jurídico: relações de poder nas decisões de conflito familiares
}

\author{
Juridical and psychosocial field: relations \\ of power in the decisions of \\ family conflicts
}

\author{
Marcia Regina Ribeiro dos SANTOS \\ Liana Fortunato COSTA ${ }^{2}$
}

\begin{abstract}
Resumo
Este artigo discute, a partir da experiência adquirida por profissionais psicossociais do Serviço de Atendimento a Famílias com Ação Cível do Tribunal de Justiça do Distrito Federal e dos Territórios, as relações de poder presentes nos campos familiar, psicossocial e jurídico, com base em autores da Terapia Familiar, da Psicologia Jurídica e da Sociologia que fundamentem as questões apresentadas. O caso de Lorena ilustra o poder que existe nessas relações e nas inter-relações dos diferentes campos sociais, quando os avós materno e paterno disputam sua guarda na Justiça. Embora haja interesse da equipe psicossocial em compartilhar conhecimento com os profissionais do Direito, observou-se que o poder que perpassa pelos campos aqui referidos, apenas em parte atendeu à resolução do pleito. Ao final, questiona-se quanto ao futuro da família, à eficácia do trabalho dos profissionais do setor psicossocial e à participação da Justiça na disputa.
\end{abstract}

Unitermos: Família. Fatores psicossociais. Justiça social. Poder.

\begin{abstract}
This article discusses, based on the experiences of psychosocial professionals from the "Family Support Services with Civil Action of the Court of Justice in the Federal District and Territories", the relations of power that exist in the family, psychosocial and juridical fields, based on authors of Family Therapy, Juridical Psychology and Sociology that underpin the issues presented. The Lorena case illustrates the power that exists in these relations and in the interrelationships of different social fields, when her maternal and paternal grandparents dispute her custody in court. Even though the psychosocial team has an interest in sharing knowledge with the Legal professionals, it was seen that the power that permeates the fields mentioned here only partially addressed the decision in the litigation. In terms of the future of the family, the effectiveness of the psychosocial workers and the participation of Justice in these disputes are addressed at the end of the paper.
\end{abstract}

Uniterms: Family. Psychosocial factors. Social justice. Power.

1 Tribunal de Justiça do Distrito Federal e dos Territórios, Serviço Psicossocial Forense. Palácio da Justiça, Praça Municipal, Lote 1, 70094-900, Brasília, DF, Brasil. Correspondência para/Correspondence to: M.R.R. SANTOS. E-mail: <marciarrsantos@gmail.com>.

2 Universidade de Brasília, Programa de Pós-Graduação em Psicologia Clínica e Cultura. Brasília, DF, Brasil. 
Poder em relação a quem? Poder de quem?

Poder em ação de quem para quem?

Por mais contraditório que pareça, para alcançar o equilíbrio do poder, que é o ideal, vivencia-se o desequilíbrio do poder, que é o real. Considera-se que a tônica aqui abordada não é surreal, sendo possível praticá-la sem fazer nenhum mal.

Nessa perspectiva, a sabedoria está em compreender e em reconhecer

o importante papel que o poder desempenha em nossas vidas.

Além disso, o poder causa tanto males e dissabores quanto benefícios e prazeres.

O fato é que o poder existe e existirá, enquanto vida houver!

Pois é...

(Marisa Regato)

As Ciências Políticas, a Economia, a Sociologia, a Filosofia e a Psicologia têm procurado compreender a influência do poder, nos vários aspectos da vida social, abordando-o de diferentes maneiras sem, todavia, esgotar o assunto.

A definição de poder, segundo Enriquez (2007), é bastante delicada de ser formulada, pois inclui aspectos ambíguos em seu âmbito. O poder pode ser uma posse - ter poder; pode ser uma concessão - delegar poder; um ato - tomar poder; uma renúncia - submeter-se ao poder. Para uma conceituação de poder, vários elementos devem ser considerados, tais como: o poder é apreendido na relação; o poder castra; o poder define o que deve ser feito; o poder admite a transgressão; o poder ordena; o poder tende a durar.

Em virtude da amplitude de significados existentes sobre o poder, este artigo tem por objetivo efetuar reflexões e abrir espaço para ampliar a discussão sobre as relações de poder, nos campos familiar e psicossocial jurídico, levando em conta a ética que permeia tais relações.

Sua fundamentação se apoia no posicionamento de estudiosos sobre o assunto e na observação de inúmeras famílias que buscam a Justiça, após uma separação conjugal, separação de união estável e/ou separação de relacionamento amoroso que resultou em filhos. Chama atenção o fato de as relações familiares, após a separação, serem marcadas por intensa disputa, que pode levar ao acirramento da contenda, na definição da guarda e na regulamentação de visitas dos filhos, sendo necessária a intervenção de terceiros para solucionar a questão. Esse contexto de disputa, relativo a funções conjugais/maritais, via de regra, atinge e configura o exercício dos papéis parentais.

\section{O poder nos campos familiar e psicossocial jurídico}

Para Bourdieu (1997), a noção de campo está vinculada a um espaço social de dominação e de conflito. Cada campo tem certa autonomia e possui suas próprias regras de organização e de hierarquia social, sendo estruturado por posições e relações entre as mesmas.

Na sociedade brasileira, o Poder Judiciário tem na figura do juiz de direito o representante do poder, estando ele autorizado pelo Estado a intervir no destino dos componentes das famílias em litígio, por meio das decisões que profere. Portanto, a Justiça é a instituição para a qual os indivíduos recorrem no intuito de obter respostas que solucionem suas contendas.

No caso específico do Direito de Família, o indivíduo que ajuíza uma ação vê seu pleito de forma diferente do outro, contra quem está disputando. Para decidir o litígio, ambos vão até um local - foro - em princípio, justo e neutro, ou, pelo menos, assim deveria ser, e buscam um terceiro - o juiz - que em seu papel supostamente neutro deverá decidir com base em elementos interpretativos da lei. No entanto, ele necessita de provas, isto é, de documentos que compõem o processo judicial e que atestem a veracidade e factibilidade das afirmações apresentadas a favor ou em desfavor de um ou do outro. Logo, para o Direito tem valor somente aquilo que consta no processo judicial, em decorrência da regra processual segundo a qual "O que não está nos autos, não está no mundo jurídico" (Granjeiro, 2006, p.70).

A pessoa que inicia uma ação judicial é denominada requerente, e a outra, contra a qual litiga, é denominada requerido. Ambas devem ter um representante legal - advogado constituído ou defensor público - conhecedor das leis e das normas jurídicas e, além 
disso, treinado para utilizar o código linguístico próprio do Judiciário (Granjeiro, 2006).

Entretanto, esse código linguístico se constitui em linguagem tão formal e hermética, que muitas famílias que recorrem à Justiça se sentem alijadas das decisões judiciais, em virtude de não compreenderem seu funcionamento Redação ambígua. Na linguagem jurídica, "ordenamento" quer dizer legislação. Seria "funcionamento do sistema"? "Andamento do processo"? "Determinações judiciais"?). Além disso, há casos em que os conflitos entre as famílias se intensificam, dependendo da forma como o advogado ou o defensor público expõe a situação em questão (Costa, Penso, Almeida \& Ribeiro, 2008). E o processo decisório pode se configurar para os disputantes como a escolha de quem tem razão ou de quem possui a "verdade".

Atualmente, os profissionais que atuam no setor psicossocial, quais sejam, os psicólogos e os assistentes sociais que avaliam as famílias a pedido dos juízes, buscam nas contribuições da vertente teórica do construcionismo social os subsídios para a elaboração de relatórios mais claros e consistentes, bem como para a intervenção junto às famílias. Hoffman (1998) afirma que, para essa vertente do construcionismo, não há "verdades sociais irrefutáveis, apenas histórias sobre o mundo que contamos a nós mesmos e aos outros" (p.27).

Os construcionistas sociais utilizam recursos conversacionais para enriquecer o potencial de comunicação e negociação entre as pessoas, fazendo uso de observações sobre o modo de processamento da conversa e da construção de perguntas "curiosas", a partir da posição do "não saber", uma vez que há diferentes versões narradas sobre um mesmo fato (Anderson \& Goolishian, 1998).

Frente a esse contexto, os profissionais do setor psicossocial buscam sair do discurso trazido pelos envolvidos no processo, cujo conteúdo envolve verdade/mentira, tendo em vista que tal dicotomia mais aprisiona do que liberta, além de acirrar o litígio. Questiona-se a "verdade" até então apresentada, pois se considera que essa contém significação que é própria e pessoal. Acredita-se, pois, que o construcionismo social traz, para o campo jurídico, novos paradigmas para ampliar as possibilidades de julgamento, a partir das relações, pois quem tem a melhor narrativa, consequentemente, tem mais poder.
De acordo com Grandesso (2000), narrativa é "a organização por meio do discurso, por meio de termos, símbolos ou metáforas, de um fluxo de experiência vivida, em uma sequência temporal e significativa. ... cada relato se apresenta como um ato de (re)criação isolado" (p.199). Nesse sentido, existem diferenças entre o conteúdo escrito nos autos processuais, a que os profissionais têm acesso antes de entrar em contato com a família, e as histórias narradas no momento das entrevistas realizadas diretamente com os envolvidos. Ao ouvir as famílias, os profissionais buscam apreender o significado, para aquela pessoa, da história que está sendo contada, sem, no entanto, perder de vista o campo em que tanto as famílias quanto os profissionais do Direito estão inseridos - campo jurídico - e as relações de poder nele constituídas.

Vale dizer que o campo familiar nem sempre é um local de proteção e segurança e pode ser espaço para conflitos, conforme apontam Falcão e Salomão (2005). Além disso, incluem-se os sentimentos de tristeza, dor e sofrimento que encorajam as pessoas a recorrer à Justiça, a fim de solucionar os desentendimentos nos quais estão paralisados. Nesse contexto de disputa, a Psicologia busca resgatar o sofrimento e a subjetividade contida na descrição dos fatos que necessitam de um ajuizamento (Brito, 2005). Surgem, então, as questões: com relação aos distintos contextos - familiar e judicial - qual poder está em jogo? Qual a característica do exercício do poder entre os profissionais e entre os cidadãos que buscam a intervenção de um terceiro para resolver seus conflitos? Qual o papel do profissional do setor psicossocial em relação ao poder, nos campos jurídico e familiar?

Nichols e Schwartz (2007) indicam que o campo de um indivíduo é formado pelo que ele consegue perceber. Assim, uma família é um campo formado por um feixe de relações intercambiáveis entre si. A família, grupo composto por seus membros, além de ser espaço de convivência importante para o desenvolvimento destes (Neves \& Romanelli, 2006), é constituída por tudo o que cada indivíduo percebe em si e de si mesmo, no outro e do outro, em relação ao meio/contexto ao qual pertence. Nesse sentido, o campo familiar é um aspecto particular do campo social.

Intervenções com famílias, na perspectiva sistêmica, enfatizam que o trabalho deve privilegiar as 
interações do grupo familiar, e não os indivíduos per se. O conceito de campo apresentado se refere ao que os terapeutas de família afirmam: "A família é mais do que uma coleção de indivíduos separados: é um sistema, um todo orgânico cujas partes funcionam de uma maneira que transcende suas características separadas" (Nichols \& Schwartz, 2007, p.26). Assim sendo, ao se realizarem intervenções em um sistema familiar, consideram-se não apenas os indivíduos, mas também as dimensões das experiências pessoais de cada um e o contexto social ao qual o indivíduo e os sistemas estão inseridos.

Atualmente, a Psicologia Jurídica está voltada para as intervenções realizadas nas Varas da Infância e Juventude, Varas de Família e Varas Criminais, cujos profissionais utilizam diferentes recursos teóricos e metodológicos das abordagens clínicas para realizar suas observações, visando à elaboração de relatórios que possibilitem reflexões sobre a dinâmica do sujeito e de sua família. Essa perspectiva de construção do trabalho ainda está se consolidando, tendo em vista os diferentes e, às vezes, controvertidos olhares na consecução dos objetivos, no atendimento às solicitações dos juízes, sem perder de vista o apoio às famílias em seu sofrimento.

No Distrito Federal, a Psicologia Jurídica teve início na década de 1990 e desde então tem expandido sua área de atuação. De acordo com informações prestadas pela psicóloga Renata Leporate Farret, profissional do Conselho Regional de Psicologia da $1^{\text {a }}$ Região/CRP/013 ${ }^{3}$ os profissionais da Psicologia Jurídica marcam presença com atuações em órgãos da União e do Governo do Distrito Federal, tais como Tribunal de Justiça do Distrito Federal e dos Territórios (TJDFT), Ministério Público da União e do Distrito Federal e Polícia Civil, mais especificamente no Instituto de Medicina Legal Leonídio Ribeiro.

Uma particularidade que merece destaque é o crescente número de profissionais liberais - psicólogos clínicos - que se mostram interessados em realizar trabalhos que forneçam subsídios aos juízes das Varas de Família e Criminais em suas decisões, efetuando perícias às expensas dos envolvidos nas ações processuais.
Outra característica marcante no Distrito Federal, principalmente quanto aos profissionais do setor psicossocial que atuam junto às Varas de Família do TJDFT, é que esses buscam compreender a dinâmica relacional existente entre os diferentes sistemas em que estão inseridos os indivíduos que recorrem à Justiça. Com isso evita-se análise restrita dos sujeitos envolvidos em um trabalho centrado no indivíduo, o que possibilita fazer conexões entre indivíduo e sociedade e deixa de lado a dicotomia que fatalmente o apresentaria como bom ou mau (Nery \& Costa 2008).

Ainda no que concerne à Psicologia Jurídica, nota-se que o trabalho dos profissionais requer a investigação nos diferentes níveis de complexidade, ou seja, o entendimento dos fenômenos psicológicos no contexto da Justiça e em interface com o Direito, além do assessoramento direto e indireto às organizações judiciárias e às instituições que cuidam dos direitos dos cidadãos. Para tanto, os referidos profissionais se empenham em ampliar sua qualificação, recorrendo a formações que possam contribuir para melhor atendimento aos cidadãos que chegam até eles por meio do sistema judicial (Cruz, Maciel \& Ramirez, 2005).

\section{O poder do juiz de direito e dos profissionais do setor psicossocial}

O juiz tem o poder de fazer sanções e julgamentos (Granjeiro, 2006), proferindo-os a partir do conhecimento que tem da lei, poder que lhe é conferido social e legalmente em razão de sua investidura no cargo (acrescentei). Em várias ocasiões, o magistrado envia os autos processuais para a equipe psicossocial com o intuito de inserir, no "mundo jurídico", um documento - o relatório - cujo conteúdo deverá contribuir para uma decisão mais ampla e compreensiva dos conflitos presentes na ação judicial. Os profissionais do setor psicossocial, por sua vez, se manifestam e intervêm, apoderando-se do objeto que Ihes é passado - o processo -, que envolve seres humanos, suas dores, sofrimentos e histórias contadas com a percepção que cada um tem, a partir do campo em que se situa, com suas crenças e suas "verdades". Nesse sentido, entende- 
-se que, no momento em que o juiz envia o processo ao setor psicossocial, ele está interessado em conhecer a opinião de seus profissionais. Tal interesse evidencia sua motivação e preocupação em ampliar a visão que tem do campo jurídico, no qual está inserido, para melhor decidir.

Nessa perspectiva, entende-se que o poder de decisão do magistrado está sendo compartilhado com os profissionais do referido setor, que procuram dar uma visão mais humanista à letra fria da lei. Estes, por sua vez, ao aceitarem compartilhar tal poder, que é de ordem legal, realizam intervenções junto às famílias, com base no conhecimento teórico adquirido e na capacidade de apreender as subjetividades dos sujeitos envolvidos. Nessa ótica, há aceitação do status profissional que o saber oriundo das ciências humanas propicia, tendo o aval, tanto da família quanto do juiz. Percebe-se, portanto, que as áreas que atuam no âmbito judicial buscam criar espaços consensuais de conhecimento, sem que haja, entre os profissionais, "um espaço da verdade, mas um espaço de consenso, de acoplamento estrutural"(Vasconcellos, 2002, p.140).

\section{Os profissionais do setor psicossocial de varas de família}

Antes de apresentar um caso ilustrativo das relações de poder discutidas neste artigo, é importante fazer alguns comentários acerca de como se elabora o estudo avaliativo. A equipe que realiza os atendimentos é composta por profissionais de Psicologia e de Serviço Social, tendo como objeto de estudo as famílias que buscam as Varas de Família para resolver seus conflitos. O enfoque teórico utilizado é o da perspectiva sistêmica, que considera a família como um todo, enfatizando as interações no sistema e nos subsistemas (Calil, 1987).

As atividades desenvolvidas pelos profissionais, as quais proporcionam condições para a realização da avaliação da dinâmica familiar, se constituem de entrevistas com os vários membros da família. São realizadas observações com as crianças e/ou adolescentes, com os genitores e com as famílias de origem. Tais entrevistas e observações podem ser efetuadas nas salas destinadas aos atendimentos, onde a equipe trabalha, ou em visita à residência dos dois genitores ou dos avós - se estes forem os participantes principais no processo judicial -, ou ainda de outro familiar envolvido no processo (Brandão \& Costa, 2004).

A finalidade dessas ações é compor um quadro de informações que privilegiem as interações e a dimensão transgeracional dos conflitos (Penso, Costa \& Ribeiro, 2008). Essa dimensão é captada de forma mais dinâmica pela construção do Genograma, definido por Miermont (1987) como um mapa que estrutura graficamente a família ao longo de várias gerações, assim oferecendo a visualização das etapas do ciclo de vida familiar e dos movimentos emocionais ligados a elas (Lima \& Fonseca, 2008). Ademais, dependendo da situação encontrada junto ao grupo familiar estudado, podem ser feitas visitas a instituições públicas e privadas a que a família esteja vinculada, assim como podem ser estabelecidos contatos com profissionais que a acompanhem ou a tenham acompanhado.

O estudo psicossocial não tem caráter resolutivo, mas, sim, avaliativo. Daí, ao final das intervenções, serem realizados encaminhamentos para que as famílias procurem os recursos da comunidade, a fim de serem tratados os conflitos que estão gerando sofrimento, especialmente às crianças e adolescentes, os quais dependem da proteção e afeto dos adultos. Após a finalização do estudo psicossocial, é redigido um relatório, que se constitui em subsídio para a decisão do magistrado (Costa, Penso, Legnani \& Sudbrack (2009); Granjeiro \& Costa, 2008). A elaboração desse relatório, que muitas vezes se constitui em peça fundamental na decisão judicial, reveste-se da necessária preocupação ética, pois seu conteúdo pode transformar definitivamente a organização familiar e instaurar rupturas afetivas.

Assim, os profissionais do setor psicossocial têm consciência de que o seu saber significa poder (Enriquez, 2007; Foucault, 1998). Trata-se de conhecimento específico e restrito, que traz à evidência uma triangulação, como assinala Shine (2005), quando chama atenção sobre a conduta utilizada pela família em estudo, momento em que cada um vai tentar influenciar os profissionais para ter a resposta judicial a seu favor. A triangulação diz respeito à presença dos componentes antagônicos das famílias em litígio, do profissional do setor psicossocial e do profissional do Direito, que podem protagonizar disputa de poder a partir do conhecimento que têm do/no campo em que estão inseridos. 


\section{O conflito familiar de Lorena}

A história da dinâmica familiar aqui descrita ${ }^{4}$ ilustra como os vários aspectos do poder estão inseridos nesse contexto. As informações apresentadas caracterizam grande número de avaliações psicossociais realizadas nos tribunais, representando um estudo de caso no sentido clássico de pesquisa. A família foi objeto de observação nos seguintes aspectos: a força dos legados transgeracionais presentes na geração em disputa e as questões de gênero, com foco na prevalência do patriarcado. Todavia, no presente texto, a abordagem diz respeito apenas ao que se refere ao poder, nos campos psicossocial jurídico e familiar. Assim sendo, foi feito um recorte na história das famílias materna e paterna de Lorena, criança em questão.

O pedido de guarda judicial de Lorena foi efetuado pela avó materna, Geovana (43 anos), dando início, assim, ao processo que resultou em um pedido de estudo psicossocial, feito pelo juiz responsável. Geovana, solteira, balconista, teve três filhos: Vilma (falecida aos 20 anos), Fábio (18 anos) e Mirian (14 anos), sendo os dois últimos estudantes, residentes com ela. Segundo Geovana, quando seus filhos eram menores, contou com o apoio de seus pais, Joaquim (61 anos) e Eliete (59 anos), que também apoiaram Vilma na ocasião em que teve os filhos - Lara e Pedro (6 e 5 anos) -, de dois relacionamentos distintos, ajudando a cuidar dos bisnetos. Vilma, posteriormente, envolveu-se com Luiz, com quem teve uma filha, Lorena (1 ano na ocasião do estudo). 0 casal residiu (ou residia?) com os familiares maternos, tanto antes de Vilma engravidar, quanto durante a gestação e após o nascimento de Lorena. De acordo com o depoimento de Geovana, o relacionamento entre sua filha e o companheiro era permeado pela violência, e considerava ambos imaturos para assumir as responsabilidades de uma família.

Quanto aos pais de Luiz, Roberto (58 anos de idade, aposentado) e Joana (46 anos, do lar), estavam casados há cerca de 30 anos. Tiveram teve dois filhos, Luiz (24 anos, motorista de transporte alternativo) eTônia (12 anos, estudante). Os pais de Luiz, assim como a mãe de Vilma, discordavam do relacionamento do casal e entendiam que ambos não estavam preparados para desempenhar os papéis materno e paterno, já que priorizavam a diversão, em detrimento dos cuidados com a filha.

Diante da constatação de que os dois não dispensavam à filha a atenção devida, o avô paterno resolveu ajuizar Ação de Guarda contra eles, pedindo a guarda da criança. Todavia, antes de o juiz proferir a sentença, Vilma foi assassinada por Luiz, com seis tiros disparados de uma arma de fogo que ele portava. $\mathrm{Na}$ ocasião, eles estavam separados. Segundo relato do próprio Luiz, o crime aconteceu em meio a uma discussão, em razão de ele discordar das amizades que ela tinha, por ciúmes.

Após esse fato, o avô paterno teve, por escrito, a anuência do filho para ser o guardião legal de Lorena, já que ele se encontrava preso, em virtude do crime cometido. Com a cópia da certidão de óbito de Vilma, o avô obteve a guarda judicial da neta. Em várias ocasiões anteriores, ela ficara em sua casa para a mãe trabalhar, uma vez que a avó materna também trabalhava fora o dia todo. Assim, beneficiou-se da lei que possibilita a guarda aos avós quando os pais estão impedidos de ficar com a criança. Nessa ação judicial, Geovana não era parte integrante na disputa pela guarda da neta e, por isso, estava excluída do processo.

A partir da decisão judicial, foi efetuado acordo verbal entre Roberto e Geovana para que os contatos entre os familiares maternos e Lorena continuassem ocorrendo. No entanto, na prática, esses passaram a acontecer raramente e, por isso, insatisfeita, Geovana ajuizou uma ação de transferência de guarda contra Roberto. Foi a partir dessa ação que a equipe psicossocial conheceu a história de Lorena. O estudo foi realizado com o objetivo de informar ao juiz qual dos avós tinha melhores condições para exercer a guarda da neta.

A avó materna argumentou que acompanhou a gravidez da filha, o nascimento da neta e o desenvolvimento desta até a determinação de guarda para os avós paternos, a qual, segundo ela, foi obtida de forma incorreta. Geovana declarou sentir-se enganada por Roberto, haja vista ter ele utilizado a certidão de óbito de Vilma para a obtenção da guarda da criança e, com isso, excluir a família materna. Após o deferimento da guarda, a referida senhora disse que o descumprimento

558 Os nomes são fictícios para preservar a identidade dos componentes da família. 
do acordo verbal por parte de Roberto, no que diz respeito às visitas entre a família materna e a neta, fez com que, mais uma vez, ela se visse enganada por ele. Além do mais, sentia intensa mágoa de Luiz por tê-lo acolhido em sua casa e ele ter assassinado sua filha, reconhecendo-o como traidor de sua confiança. Em razão de Luiz aguardar em liberdade a decisão judicial, ele mantinha contato com Lorena durante esse período.

Os profissionais que realizaram o estudo entenderam que Lorena deveria ser cuidada pela família materna e manter contato com a paterna, pois nada havia que justificasse o contrário. No entanto, o processo retornou ao setor alguns meses depois sem alteração de guarda, permanecendo Geovana em situação desfavorável, pois os contatos com a neta continuavam reduzidos. O juiz havia determinado o retorno do processo para avaliar a condição emocional da avó materna para cuidar da neta e, para tanto, a equipe deveria observar o comportamento das duas durante atendimentos que seriam realizados no setor responsável.

\section{As relações de poder no campo familiar de Lorena}

O nascimento de Lorena trouxe ao casal esperança de uma nova vida e novas possibilidades. Os pais tentaram se manter juntos por algum tempo, porém as dificuldades relacionais permaneceram. Geovana ajudava-os o quanto podia, amenizando os desentendimentos existentes, apoiando-os. Roberto, insatisfeito com o comportamento de Luiz e Vilma em relação à neta, e percebendo que as orientações que dava ao filho não eram por ele consideradas, sentiu-se desafiado por Luiz, recorrendo ao poder judicial. Com essa atitude, que evidencia proteção à sua descendente, reafirma a desqualificação do papel de Luiz como pai, denuncia judicialmente o despreparo dos pais nos cuidados e proteção de sua neta e tenciona buscar em sua família contexto harmonioso e socialmente produtivo, conforme mencionam Falcão e Salomão (2005).

De acordo com Foucault (1998), o poder está nas relações sociais e é uma prática social. Para o terapeuta de família Ausloos (1996), no caso das famílias litigantes, "o poder está no jogo do sistema e, portanto, cada elemento participa na sua distribuição, na sua gestão, na sua utilização" (p 54).

A experiência com as famílias que são atendidas no Serviço Psicossocial tem mostrado que a busca à
Justiça pode significar tanto um pedido de ajuda a um terceiro, que detém o poder para decidir sobre as contendas não-resolvidas, quanto o fortalecimento de seu posicionamento, que pode evidenciar um enrijecimento na posição assumida.

As relações familiares são intrincadas, e cada ator envolvido em uma disputa se coloca como detentor da "verdade". Também, aquele que vencer o processo será visto como o que possui a"verdade" dos fatos, obtendo um ganho pessoal e também social, pois a "verdade" vencedora será apresentada à criança, à família de origem e à sociedade. Ademais, a obtenção do pedido judicial em favor daquele que se encontra enrijecido no posicionamento o fortalece e lhe dá poder de argumentação, enquanto o outro, que não conseguiu ter a prevalência de seus interesses, tem sua autoestima diminuída, assim como também reduzida a crença na Justiça, ou melhor, acredita que não se fez justiça.

Lorena nasceu e cresceu em um contexto de desentendimentos entre seus avós e seus pais. Os avós não conseguiam qualificar positivamente os filhos, tanto no que se refere às escolhas afetivas que fizeram, quanto à assunção do papel parental. Os filhos, por sua vez, não conseguiam se autoafirmar nas tentativas que faziam para se tornar independentes e autossuficientes em seus novos papéis. Nesse sentido, os conflitos de poder entre os participantes desses subsistemas são evidentes, alternando-se e sobrepondo-se momentos de expressões desse mesmo poder. Por conseguinte, é exatamente em situações como essa que as famílias, não encontrando em seu âmbito de negociação respostas que atendam aos interesses dos seus membros e, muito menos, aos das crianças/adolescentes envolvidos, buscam a Justiça, como último recurso para resolver a contenda e aliviar o sofrimento.

Pesquisadores da área de família dizem que, quando os membros do grupo familiar estão em conflito, não há disposição para que haja diálogo que favoreça a libertação dos problemas por eles vivenciados. No caso dos profissionais que atuam no contexto jurídico, estes são permanentemente desafiados a sentir diferentes emoções quando atendem famílias litigantes, pois acabam se identificando com a dor e o sofrimento delas (Ribeiro \& Costa, 2007). Por essa razão, necessitam desenvolver habilidade e competência para lidar com o alto grau de tensão expressa pela violência trazida pelas referidas famílias, que constantemente os convoca a tomar partido e a julgar suas "verdades". 
Roberto, com o assassinato da mãe de Lorena por seu filho, a partir do campo em que está inserido, excluiu da vida da neta a família materna, sendo apoiado pela Justiça, ao ter atendido o seu pleito. A partir desse momento, sentiu-se vitorioso, tanto sobre o filho quanto sobre a família de Vilma e perante a sociedade, pois passou a ser detentor do poder legal de Lorena. Geovana, por sua vez, sentiu-se triplamente desam-parada: teve a filha assassinada, foi impedida de conviver com a neta e foi desconsiderada pela Justiça, que não a ouviu. $\mathrm{Na}$ percepção dessa senhora, o poder da Justiça estava favorecendo e fortalecendo a injustiça, pois, na sua percepção, o juiz havia tomado partido, julgando com parcialidade a "verdade" contida no discurso escrito.

Nessa perspectiva, ela visualizava a violência na família paterna como sendo explícita e, além disso, corroborada pela Justiça. Por sua vez, evitava a exposição da violência em forma de revide pela morte de um de seus integrantes, e buscava agir de acordo com a lei socialmente aceita, a fim de retomar o poder, para ela, enfraquecido, com o ajuizamento de uma nova ação judicial. Nessa família, a violência estava implícita, contida pelo sentimento misto de raiva e de medo, tanto pelo que a família paterna ainda poderia fazer contra ela, quanto pelo que sua própria família poderia fazer contra a outra.

Os profissionais compreenderam que a dinâmica relacional existente evidenciava o poder do mais forte no discurso argumentativo escrito e falado. Em sendo assim, ao realizarem o estudo, efetuaram intervenções por meio da linguagem discursiva junto à família, e textual, junto ao juiz. A equipe, avaliando que Roberto teve o respaldo da Justiça no exercício do poder de decisões acerca do bem-estar da neta, buscou oferecer um contexto de reflexão para Geovana. Concluiu que ela tinha plenas condições para exercer o papel de cuidadora de Lorena, podendo ser responsável pela guarda da neta, não se observando impeditivo para a convivência entre elas.

\section{Considerações Finais}

As dinâmicas relacionais apresentadas pelas famílias em litígio, que objetivam a guarda de filhos ou netos, envolvem disputas de poder. Percebe-se que tais interações fazem parte não apenas das instâncias do grupo familiar em estudo, mas se dão também entre os profissionais do setor psicossocial e os membros da família, e entre esses profissionais e os do Direito, levando em conta os diferentes paradigmas teóricos utilizados pelos diversos ramos do conhecimento.

Acredita-se que cada membro da família tem o poder e a competência de encontrar alternativas menos litigantes para suas dificuldades, porém, no momento em que buscam a ajuda da Justiça, estão todos tão implicados na disputa, que não conseguem enxergar possibilidades diferentes e que gerem menos sofrimento. Aliás, frequentemente, quando os membros de uma família encontram caminhos para solucionar as contendas existentes, a dinâmica de beligerância agrava-se, e a saída consiste em delegar a um terceiro juiz - o poder de decidir o destino de todos a partir da sentença judicial.

A trajetória das famílias que passam por uma avaliação psicossocial na Justiça mostra, e o caso aqui ilustrado confirmou, quão intensa é a disputa pelo poder. Os componentes das famílias, envolvidos no processo, muitas vezes entendem que se faz "justiça" quando a autoridade judicial decide em favor de quem consegue provar a incapacidade do outro. Tal situação parece ter sido evidenciada na família de Lorena.

Com relação ainda ao caso apresentado, entendeu-se que havia dúvidas por parte do juiz sobre a capacidade da avó materna de cuidar e proteger a neta, haja vista o retorno dos autos para nova avaliação psicossocial. Acredita-se que a linguagem utilizada no relatório não conseguiu demonstrar o potencial de proteção e de acolhimento que Geovana poderia oferecer a Lorena. Depreendeu-se também que o avô, apoiado pelo discurso escrito de seu advogado, conseguiu manter-se no poder de ser o guardião legal de Lorena, pelo menos durante a realização dos dois estudos psicossociais.

Assim, o compartilhamento de conhecimento da equipe psicossocial jurídica com os profissionais do Direito, nesse caso, não ocorreu, demonstrando que sua prática encontra-se ainda distante. O poder, que perpassa por todas as instâncias dos campos aqui referidos - familiar, psicossocial e jurídico -, com ênfase na decisão judicial, apenas em parte atendeu à resolução da contenda, uma vez que avó e neta mantiveram-se distanciadas, agora com o aval da Justiça. 
Nesse sentido, alguns questionamentos se tornam procedentes: no campo familiar, que envolve os sistemas familiares materno e paterno, que histórias seriam contadas a Lorena, em relação a seus pais, tios e avós? Teria a família materna chance de contar a sua versão? E a convivência entre a família materna e a criança? Estariam ambas "condenadas" a se manterem separadas? No campo psicossocial jurídico, teria o trabaIho realizado pela equipe sido ineficaz para fornecer os subsídios necessários para o equilíbrio na tomada de decisão pelo magistrado quanto ao pedido formulado pela avó? Não havendo nada que a desabonasse para assumir a guarda da neta, a sua concessão não revelaria um viés humanitário da Justiça, no sentido de compensar a perda sofrida? Haveria questões relativas aos gêneros masculino e feminino implícitas no aspecto decisório?

Tais questionamentos, só o tempo poderá responder. Ficam para reflexão.

\section{Referências}

Anderson, H., \& Goolishian, H. (1998). O cliente é o especialista: a abordagem terapêutica do não-saber. In S. McNamee \& J. K. Gergen (Orgs.), A terapia como construção social (pp.34-50). Porto Alegre: Artes Médicas.

Ausloos, G. (1996). A competência da família: tempo, caos e processo. Coleção sistemas, famílias e terapias. Lisboa: Climepsi editores.

Bourdieu, P. (1997). Meditações pascalianas. Rio de Janeiro: Bertrand Brasil.

Brandão, S. N \& Costa, L. F. (2004). Visita domiciliar como proposta de intervenção comunitária. In M. A. Ribeiro \& L. F. Costa (Orgs.), Família e problemas na contemporaneidade: reflexões e intervenções do Grupo Socius (pp157-179). Brasília: Universa.

Brito, L. M. T. (2005). Reflexões em torno da psicologia jurídica. In R. M. Cruz, S. K. Maciel \& D. C. Ramirez (Orgs.), O trabalho do psicólogo no campo jurídico (pp.9-17). São Paulo: Casa do Psicólogo.

Calil, V. L. L. (1987). Terapia familiar e de casal. São Paulo: Summus.

Costa, L. F., Penso. M. A., Almeida, T. M. C, \& Ribeiro, M. A. (2008). A justiça é demorosa, burra e cega, percepções de famílias sobre a dimensão jurídica dos crimes de abuso sexual. Boletim de Psicologia, 58 (128), 85-102.

Costa, L. F., Penso, M. A., Legnani, V. N. \& Sudbrack, M. F. O. (2009). As competências da Psicologia Jurídica na avaliação psicossocial de famílias em conflito. Psicologia \& Sociedade, 21 (2), 233-241.

Cruz, R. M., Maciel, S. K. \& Ramirez, D. C. (2005). Apresentação. In R. M. Cruz, S. K. Maciel, \& D. C. Ramirez, (Orgs.), O trabalho do psicólogo no campo jurídico (pp. 7-8). São Paulo: Casa do Psicólogo.
Enriquez, E. (2007). As figuras do poder.. São Paulo: Via Lettera Falcão, D. V. S \& Salomão, M. N. R. (2005). O papel dos avós na maternidade adolescente. Estudos de Psicologia (Campinas), 22 (2). Recuperado em junho 2, 2010, disponível em http://www.scielo.br. doi: 10.1590/S0103-166 X2005000200010.

Foucault, M. (1998). Microfísica do poder. Rio de Janeiro: Graal.

Grandesso, M. A. (2000). Sobre a reconstrução do significado: uma análise epistemológica e hermenêutica da prática clínica. São Paulo: Casa do Psicólogo.

Granjeiro, I. A. C. L. (2006). Psicologia e direito: interdisciplinaridade no conflito familiar violento. Dissertação de mestrado não-publicado, Universidade de Brasília.

Granjeiro, I. A. C. L, \& Costa, L. F. (2008). O estudo psicossocial forense como subsídio para a decisão judicial na situação de abuso sexual. Psicologia: Teoria e Pesquisa, 24 (2), 161-169.

Hoffman L. (1998). Uma postura reflexiva para a terapia de família. In S. McNamee \& J. K Gergen (Orgs.), A terapia como construção social (pp.13-33). Porto Alegre: Artes Médicas.

Lima, H. G. D.\& Fonseca, M. A. M. (2008). O Estudo psicossocial e a "Nova justiça". In L. F. Costa \& H. G. D. de Lima (Orgs.), Abuso sexual. a justiça interrompe a violência (pp.19-32). Brasília: Liber Livros.

Miermont, J. (1987). Dictionnaire des Thérapies Familiales. Paris: Payot.

Nery, M. P. \& Costa, L. F. (2008). A pesquisa em psicologia clínica: do indivíduo ao grupo. Estudos de Psicologia (Campinas), 25 (2). Recuperado em junho 2, 2010, disponível em http://www.scielo.br, doi: 10.1590/S0103-16 6×2008000200009.

Neves, A. S., \& Romanelli, G. (2006). A violência doméstica e os desafios da compreensão interdisciplinar. Estudos de Psicologia (Campinas), 23 (3), Recuperado em junho 2, 2010, disponível em http://www.scielo.br, doi: 10.1590/ S0103-166X2006000300009.

Nichols, M. P. \& Schwartz, R. C. (2007). Terapia familiar conceitos e métodos (7a ed). Porto Alegre: Artmed.

Penso, M. A., Costa, L. F., \& Ribeiro, M. A. (2008). Aspectos teóricos da transmissão geracional e do genograma. In M. A. Penso \& L. F. Costa (Orgs.), A transmissão geracional em diferentes contextos; da pesquisa à intervenção (pp.9-23). São Paulo: Summus.

Ribeiro, R., \& Costa, L. F. (2007). As emoções do profissional psicossocial frente à situação de abuso sexual infantil. Estilos da Clínica, 12 (23), 130-147.

Shine, S. (2005). Avaliação psicológica em contexto forense. In S. Shine (Org.), Avaliação psicológica e lei: adoção, vitimização, separação conjugal, dano psíquico e outros temas (pp.1-18). São Paulo: Casa do Psicólogo.

Vasconcellos, M. J. E. (2002). Pensamento sistêmico: o novo paradigma da ciência. São Paulo: Papirus.

Recebido em: 6/11/2008

Versão final reapresentada em: 19/7/2010

Aprovado em: 17/8/2010 
